Article

\title{
Social Welfare Evaluation of Electric Universal Service in China: From the Perspective of Sustainability
}

\author{
Huiru Zhao, Sen Guo *, Qi Zhang and Chunjie Li \\ School of Economics and Management, North China Electric Power University, \\ Beijing 102206, China; E-Mails: zhaohuiru@ncepu.edu.cn (H.Z.); \\ zhangqixiaozi234@163.com (Q.Z.); lichunjie@ncepu.edu.cn (C.L.) \\ * Author to whom correspondence should be addressed; E-Mail: guosen@ncepu.edu.cn \\ or guosen324@163.com; Tel.: +86-158-1142-4568; Fax: +86-10-8079-6904.
}

Received: 19 May 2014; in revised form: 18 July 2014 / Accepted: 25 July 2014 /

Published: 5 August 2014

\begin{abstract}
Electric universal service aims to improve the individual living quality in remote and underdeveloped areas, the implementation of which can promote the sustainable development of people's lives and the local economy to some extent. A social welfare evaluation model of electric universal service was proposed, which was divided into economic and non-economic welfare evaluation models. After the factors influencing the social welfare sense of electric universal service were identified from the perspective of sustainability, the economic welfare evaluation model was built based on Atkinson's social welfare function, and the non-economic welfare evaluation model was constructed based on the ideological connotation of prospect theory. Taking Yunnan province in China as the example, a social welfare evaluation of electric universal service was performed. The result shows that the social welfare of electric universal service for Yunnan rural areas has increased by $9.79 \%$ from 2006 to 2011 , and the "electric service realization degree" is the most sensitive indicator.
\end{abstract}

Keywords: electric universal service; social welfare evaluation; Atkinson's social welfare function; prospect theory; sustainability; China 


\section{Introduction}

Increasing the energy universal service level to improve people's wellbeing is quite important for China's sustainable energy development. Nowadays, as one of the basic energy sources, electric power is essential for people's survival and the normal operation of society. Therefore, the significance of popularizing electric service is evident. In China, solving problems, such as the electricity shortage in undeveloped and remote areas, can promote both the individual living standard and regional economic development, which is the duty-bound social responsibility of the Chinese government. "China's Energy Policy (2012)" issued by the State Council of the People's Republic of China has proposed: (1) increasing the financial investment to solve the electricity-free issues in Tibet, Qinghai, Xinjiang, Yunnan, Inner Mongolia and Sichuan provinces; (2) establishing and improving the electric universal service system with the function of social public service in densely inhabited areas without electricity; and (3) basically solving the electricity-free problem for the rural area population before the end of 2015 [1].

Being a public service project, electric universal service aims to improve the individual living quality in remote and underdeveloped areas, the implementation of which can promote the sustainable development of the local economy and individual living. The electric universal service is led by the government, implemented by the electric power enterprises and provides benefits to the whole of society. The electric universal service holds the same characteristics as other universal services, which are: (1) the scope of universal service should be the majority of electricity consumers; (2) the universal service pricing should be acceptable for electricity consumers; and (3) the universal service quality should be guaranteed [2]. The implementation of electric universal service can improve the social welfare and promote sustainable development of the whole society. Analyzing the implementation effect of electric universal service can identify the social and economic returns of electric universal service as a public service project led by the government. Therefore, an evaluation model on the social welfare of electric universal service should be proposed, and then, a social welfare evaluation of electric universal service should be performed based on the proposed model.

With regard to the current research on social welfare, most researchers put their emphasis on two aspects, which are the social welfare function and the social welfare assessment related to specific practical issues. In terms of the social welfare function, Hanany [3] proposed an ordinal Nash social welfare function based on risk preferences assuming a common, worst social state (origin) for all individuals. Sethuraman et al. [4] characterized the class of anonymous and monotonic Arrovian social welfare functions on domains without Condorcet triples and described a domain where anonymous and monotonic Arrovian social welfare functions exist only when there are an odd number of agents. Alain Trannoy [5] used equivalence scales as the right weights of the social welfare function when needs differ. Wada [6] proposed a divisor apportionment method, which links Stolarsky mean apportionment methods to Kolm-Atkinson social welfare maximization and to generalized entropy minimization. Keller [7] generalized Kalai's results to a broader class of distributions of the individual preferences and obtained new lower bounds on the probability of a rational outcome in several classes of the generalized social welfare function. In terms of the social welfare assessment of specific practical issues, Zaharieva [8] proposed an equilibrium matching model to study social welfare and wage inequality considering a job search through personal contacts that can generate wage premiums or penalties 
depending on the parameter of bargaining power. Neil et al. [9] studied the social security, growth and welfare in overlapping generations' economies with or without annuities by employing a stylized pay-as-you-go (PAYGO) social security program. Rousse [10] provided theoretical arguments about the potential welfare-decreasing impact of citizen's participation when at least one of these assumptions was violated and recommended a limited participation of individuals in permit schemes while encouraging a better diffusion of information toward this class of potential participants. Kim et al. [11] proposed a distributed task allocation algorithm for a team of robots with resource constraints inspired by social welfare in economics, and social welfare based on the task allocation method positioned a robot team appropriately in preparedness for dynamic future events and enabled them to achieve the objectives of the system flexibly depending on the application context. Mæstada et al. [12] reconsidered the properties of applied social welfare functions to combine efficiency and equity considerations in the social valuation of health allocations and concluded that one should be cautious in applying the standard welfare economic framework to the allocation of health. Schlör et al. [13] used the Atkinson index based on a social welfare function as an analytical tool to examine the interactions between economic activity and energy services. Nabavia et al. [14] presented a fuzzy-based genetic algorithm to maximize total system social welfare by the best placement and sizing of Thyristor-Controlled Series Capacitor (TCSC) and Static Synchronous Series Compensator (SSSC) devices, considering their investment cost in a double-sided auction market. Lipow et al. [15] suggested that offering recruits an option to serve as reservists enhances social welfare if there is a sufficiently strong relationship between recruit performance in the military and their expected civilian income. Murakami [16] studied the time effect of low-cost carrier entry and social welfare in U.S. large air markets and draws the conclusion that the impact of low-cost carriers' entries did not differ between the entry year and the second year and that the social welfare gains are substantial; $90 \%$ of welfare gains come from the gain in consumers' surplus. Pirnia et al. [17] studied the policy implications of Ontario's Feed-in-Tariffs (FIT) on overall societal welfare and suggested that, if unbounded, existing FIT would have a large negative impact on consumer welfare, with an overall net loss on total social welfare. Kanakasabapathy [18] studied the economic impact of pumped storage power plant on the social welfare of electricity market and draws the conclusion that energy trading by pumped storage can increase the overall social welfare of the market.

From the above literature reviews, it can be seen that current studies related to social welfare in the field of energy and electricity are few. To the best of our knowledge, the social welfare evaluation of electric universal service has rarely been studied. Therefore, proposing an appropriate model to evaluate the social welfare of electric universal service is quite necessary, which can fill the research gap. Meanwhile, the social welfare evaluation result of electric universal service can provide some reference for the administrative department's policy making related to electric universal service and the effective provision of electric universal service by the electric power company.

Different from goods in the competitive market, the utility of electric universal service cannot be analyzed by the competitive equilibrium (Pareto optimality) theory. The electric universal service is advanced by government public policies, and the object is vulnerable groups. The welfare feeling of service-acquired individual has obvious subjectivity. Influenced by some factors, such as income level, cultural background and consumption habit, different individuals have different welfare feelings when enjoying the same electric universal service. The disparity of individual utility 
ordering due to individual different rationality cannot be ignored, which will lead to the diversity of the utility evaluation.

Considering the individual subjective judgment factors and objective factors, this paper proposes an evaluation model for the social welfare of electric universal service by employing Atkinson's social welfare function and the ideological connotation of the prospect theory from the perspective of sustainability. This paper is organized as follows: Section 2 introduces the meaning of electric universal service in China and its social welfare. Section 3 identifies the factors influencing the social welfare sense of electric universal service from the perspective of sustainability. A social welfare evaluation model of electric universal service is proposed in Section 4, which is divided into an economic welfare evaluation model and a non-economic welfare evaluation model. Taking Yunnan province in China as the example, the empirical analysis is performed in Section 5. Section 6 concludes this paper.

\section{Electric Universal Service in China and Its Social Welfare}

\subsection{Electric Universal Service in China}

Electric universal service, led by the government, is reflected by the universal service projects in the electricity field. The driving mechanism of universal service implementation is to promote economic growth and realize income redistribution by means of the positive externality of the electric power grid and, finally, to promote social equality. To be specific, there are three functions of electric universal service:

(1) Electric universal service implementation is conducive to the positive externality of the electric power grid;

(2) Electric universal service can be seen as a special redistribution means;

(3) Electric universal service contributes to implementing the government's regional development planning.

Electric universal service in China is still in the exploratory stage, and its implementation faces many issues. In the face of the uneven development of different regions in China, it is necessary to coordinate the development between different areas by implementing public policies related to electric universal service, which cannot only alleviate the infrastructure bottleneck pressures in underdeveloped and remote areas, but also be free of vast financial investment from the government. Therefore, the electric universal service in China should consider the government as the responsibility subject, the electric power enterprise as the main implementation subject and the electric power supervision department as the regulatory subject, just as shown in Figure 1. By means of cost compensation, income compensation, support funds, etc., the implementation subject of electric universal service and a part of the low-income groups can receive compensation, and then, electric service with a reasonable price can be provided. 
Figure 1. The subjects of electric universal service in China.

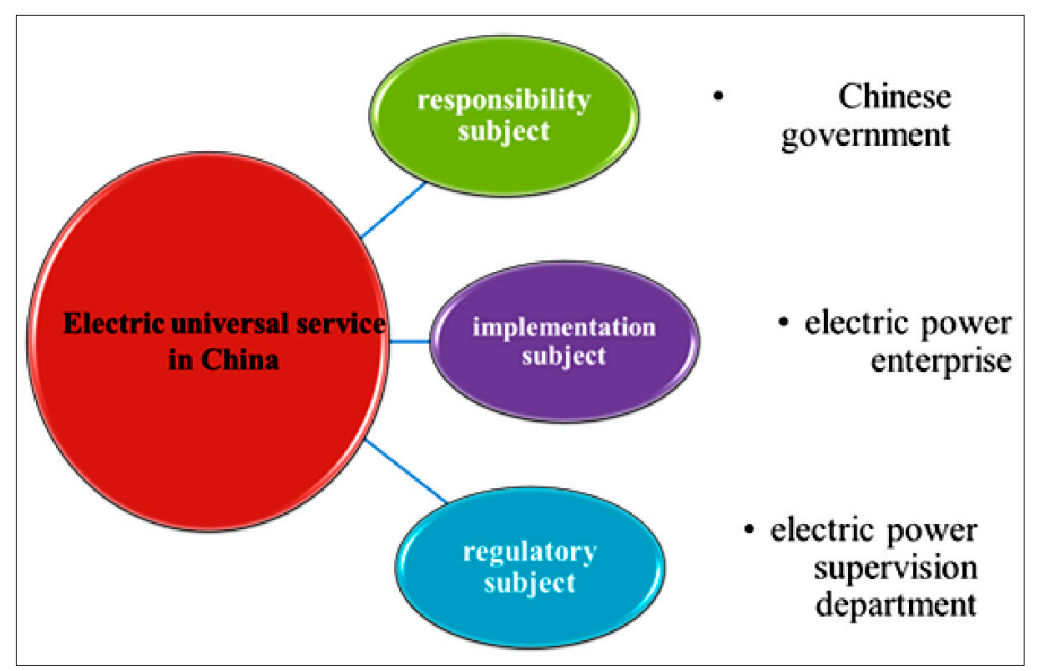

\subsection{Social Welfare of Electric Universal Service}

Social welfare is a term widely used in modern society, and different people have different opinions about its meaning. Social welfare involves people's subjective feeling and the actual life state and relates to a variety of social issues. From the general meaning, welfare refers to the various conditions making people's lives happy, which includes obtained protection and care for the individual's body and various factors affecting the free development of an individual's intelligence and spirit. However, the meaning of social welfare is beyond the individual scope, which requires one to consider the way to live a better life from the social aspect. The issue related to social welfare involves two main points, i.e., (1) what the society should do to help people live a happy life; and (2) what kind of regime and policy the society should undertake to guarantee people's happiness.

Therefore, the social welfare of electric universal service refers to the welfare brought by the implementation of electric universal service led by the government and implemented by electric power enterprises in an economy-acceptable and quality-guaranteed way. The implementation of electric universal service can make the inhabitants living in the remote and poor mountain areas obtain welfare benefits from electricity consumption. With the implementation of electric universal service, according to the policies related to electric universal service, more and more inhabitants will have access to basic electricity service. The improvements of economic conditions, as well as psychic gratification due to the electric universal service implementation are the primary sources of the social welfare effect of electric universal service. Through enjoying the electric universal service, the inhabitants can experience a happier and more satisfying life and, then, have more attention and concentrate their efforts on daily work or social activities, which will surely promote individual sustainable development.

\section{The Factors Influencing Social Welfare Sense of Electric Universal Service}

The concept "welfare sense" emphasizes the individual's subjective feeling, which stems from individual evaluation of his/her own welfare. In the process of welfare evaluation, an individual reference standard not only includes one's own objective conditions, but also considers comparison with others. The comparison of individual welfare changes with the adopted different reference 
standards. Therefore, purely taking the objective economic utility as the standard of welfare evaluation is incomplete. Meanwhile, the differences between economic level, living standard and cultural custom of universal service recipients make their service understanding and welfare sense largely different, and the individual demand for electric universal service is also different. In other words, the individual subjective feeling can exert a great influence on their welfare sense. Therefore, the individual subjective factors should not to be ignored when the social welfare sense of electric universal service is evaluated. In a word, the evaluation of the social welfare of electric universal service should include both objective factors and subjective factors, which can be represented by economic welfare factors and non-economic welfare factors, respectively.

When selecting the factors influencing the social welfare sense of electric universal service, the scientific, objective, maneuverable and pertinent principles should be followed. Considering the subjective and objective factors of service recipients affecting the welfare sense of electric universal service, as well as the current development situation related to the electricity distribution and a resident living in China, the factors influencing the social welfare sense of electric universal service are identified by the Delphi method [19], the literature review method and the on-spot interview method. By reviewing related literature and conducting on-spot interviews, the initial and important factors are identified. Then, the questionnaires, including initial factors, are distributed to experts and practitioners. Through analyzing the questionnaire results, the key and representative factors are finally determined from the perspective of sustainability, which are listed in Table 1. From Table 1, it can be seen that the factors influencing the social welfare sense of electric universal service, which is also called the index system of social welfare evaluation of electric universal service, are composed of four first-grade indexes and ten second-grade indicators. The four first-grade indexes are financial situation, family status, electric service condition and education level, as well as vocational status, respectively. The ten second-grade indicators are per capita disposable income, income satisfaction degree, the Gini coefficient, living satisfaction degree, electric service satisfaction degree, electricity price level, annual electricity consumption, electric service realization degree, educational level and vocational recognition degree, respectively.

When the disposable income of a person increases, on the one hand, he/she can consume more goods or new goods that he/she wants to buy, which can improve the living standard, which can promote personal sustainable development; on the other hand, the capability to shield against risks, such as illness and sudden accidents, can be enhanced, which can promote the harmonious and sustainable development of a family. When a person feels more satisfied with income, he/she can pay more attention to individual working and future development, which can promote social sustainable development. The Gini coefficient is a measure of statistical dispersion intended to represent the income distribution of a nation's residents. The larger the Gini coefficient is, the stronger the inequality degree. Therefore, when the Gini coefficient becomes larger, the inequality of income or wealth in the society is greater, which is not beneficial to social sustainable development. When a person feels happier with his/her living, he/she has a good atmosphere and more willingness to work hard, which can improve the individual living condition and then promote individual sustainability. Electric service level is an important factor reflecting the satisfaction degree of electricity consumers for electricity goods provided by electric power company. Electric service level reflects the opportunity of a person sharing energy resources in a society, which embodies the energy equality. 
The higher the electric service satisfaction or realization degree is, the more the equality of a person sharing energy resources. The electricity price is related to individual disposable income. A proper and fair electricity price can guide a person to do the right thing with limited income. Education and vocation also have a close relationship with individual development. A person who receives higher education usually has more chances to realize individual ideal and life values, which is more conducive to promoting individual sustainable development. Therefore, from the above analysis, we can see that the selected factors are quite related to sustainability.

Among the second-grade influencing factors, indicators $\mathrm{B}_{1}, \mathrm{~B}_{3}, \mathrm{~B}_{6}$ and $\mathrm{B}_{7}$ are the objective factors, the values of which come from objective economic data obtained by statistical materials; indicators $\mathrm{B}_{2}$, $\mathrm{B}_{4}, \mathrm{~B}_{5}, \mathrm{~B}_{8}, \mathrm{~B}_{9}$ and $\mathrm{B}_{10}$ are the subjective factors, the values of which come from individual scoring according to their own situations. The objective factors stand for the practical utilities of electric universal service recipients, while the subjective factors stand for the emotional utilities.

Table 1. Index system of the social welfare evaluation of electric universal service.

\begin{tabular}{|c|c|c|}
\hline \multirow{2}{*}{ Object } & First-grade index, & Second-grade indicator \\
\hline & $\mathbf{A}_{\mathbf{i}}$ & $\mathbf{B}_{\mathbf{j}}$ \\
\hline \multirow{10}{*}{$\begin{array}{l}\text { Social welfare of electric } \\
\text { universal service, } X\end{array}$} & \multirow{2}{*}{ Financial situation, $\mathrm{A}_{1}$} & Per capita disposable income, $\mathrm{B}_{1}$ \\
\hline & & Income satisfaction degree, $\mathrm{B}_{2}$ \\
\hline & \multirow{2}{*}{ Family status, A2 } & Gini coefficient, $B_{3}$ \\
\hline & & Living satisfaction degree, $\mathrm{B}_{4}$ \\
\hline & \multirow{4}{*}{ Electric service condition, $A_{3}$} & Electric service satisfaction degree, $B_{5}$ \\
\hline & & Electricity price level, $\mathrm{B}_{6}$ \\
\hline & & Annual electricity consumption, $\mathrm{B}_{7}$ \\
\hline & & Electric service realization degree, $\mathrm{B}_{8}$ \\
\hline & \multirow{2}{*}{$\begin{array}{c}\text { Education level, as well as vocational } \\
\text { status, } \mathrm{A}_{4}\end{array}$} & Educational level, $\mathrm{B}_{9}$ \\
\hline & & Vocational recognition degree, $\mathrm{B}_{10}$ \\
\hline
\end{tabular}

\section{Social Welfare Evaluation Model of Electric Universal Service}

The social welfare of electric universal service can be divided into two parts, i.e., economic welfare and non-economic welfare. Economic welfare stands for the objective aspect of the social welfare of electric universal service; while the non-economic welfare stands for the individual subjective aspect.

\subsection{Economic Welfare Evaluation Model}

Economic welfare reflects a part of the social welfare, which is represented by the objective economic benefits. The construction of the economic welfare evaluation model is based on the objective influencing factors of the social welfare sense of electric universal service, namely indicators $\mathrm{B}_{1}, \mathrm{~B}_{3}, \mathrm{~B}_{6}$ and $\mathrm{B}_{7}$.

Among the four objective factors mentioned above, indicator $\mathrm{B}_{1}$ (per capita disposable income) is one of the most important factors determining the individual welfare. The individual welfare depends first on the individual income, and the higher the individual income, the larger the individual welfare. According to the theory of welfare economics, the welfare sense derived from the individual income will be affected by the equality degree of income distribution. In the case of fair income distribution, 
the values of individual income and corresponding welfare are equal. However, in other cases, the unfair degree of income distribution shows the positive correlation with the gap between individual income and corresponding welfare. Therefore, from the statistics perspective, the adverse effect due to the income distribution inequality should be eliminated during the economic welfare evaluation of electric universal service. The per capita disposable income reflects the economic benefits obtained by the whole society under the environment of electric universal service, but it neglects the income distribution. Therefore, the indicator $\mathrm{B}_{3}$ (Gini coefficient) is employed to consider the influence on individual subjective feeling from the unfair income distribution. The indicators $\mathrm{B}_{6}$ (electricity price level) and $\mathrm{B}_{7}$ (annual electricity consumption) can reflect the electricity consumption status of the whole society under the environment of electric universal service, both of which can reflect the implementation effect of electric universal service intuitively. The electric universal service with an effective electricity pricing mechanism can allow the inhabitant to afford the electricity consumption, maintain the stability of social electricity consumption and even promote electricity consumption. Part of the economic welfare due to electric universal service implementation can be measured by the proportion of electricity consumption expenditure in the national net income. The proportion of electricity consumption expenditure in per capita disposable income shows an inverse relationship with economic welfare, namely the higher the former, the lower the latter.

In this paper, the Gini coefficient, which is the standard measure indicator of inequality in a society, is employed to replace the income inequality coefficient of Atkinson's social welfare function [20]. The Gini coefficient varies between zero, which reflects complete equality, and one, which indicates complete inequality. Therefore, the proportion of electricity consumption expenditure in the national net income under the environment of electric universal service can be measured by Equation (1).

$$
A=\frac{p \times Q}{I \times(1-G) \times N}
$$

where $p$ represents the electricity price; $Q$ represents the national electricity consumption; $I$ represents per capita disposable income; $G$ represents the Gini coefficient; $N$ represents the population size.

For Equation (1), $p \times Q$ represents the electricity consumption expenditure, $I \times N$ represents the disposable income of people in a group and $I \times(1-G) \times N$ represents the disposable income of people eliminating the inequality factors.

Thus, the economic welfare of electric universal service can be measured by Equation (2).

$$
E=1-A=1-\frac{p \times Q}{I \times(1-G) \times N}
$$

where $E$ represents the economic welfare index of electric universal service.

From the foregoing, the economic welfare of electric universal service is by no means a simple accumulation of various economic benefits, but pays more attention to the "efficiency" of economic benefits, which means that the individual social welfare sense of electric universal service related to economic benefits is more emphasized. 


\subsection{Non-Economic Welfare Evaluation Model}

Non-economic welfare, which cannot be measured by monetary value, is mainly represented by the improvement of human wellbeing. From the perspective of individual environmental difference and individual rational diversity, the non-economic welfare should be characterized by the individual subjective feeling factors of electric universal service. As discussed above, the subjective factors affecting the social welfare sense of electric universal service are income satisfaction degree, living satisfaction degree, electric service satisfaction degree, electric service realization degree, educational level and vocational recognition degree. These indicators' values can be obtained by individual scoring.

According to the prospect theory, the comparison between the individual prospection and reality, as well as the status of individuals will affect the preference selection on the losses and gains, both of which map to the value function [21,22]. Applying this thought of prospect theory into the issue of social welfare of electric universal service, we can determine that the individual subjective judgment on welfare with different reference standards is the primary source of the individual welfare sense difference of electric universal service. The above six subjective factors perform the judgment on individual living, as well as the satisfaction and rationality about electric service, and they also make the subjective determination on the welfare, taking other individuals' status as the reference.

The influencing factors of non-economic welfare make different contributions to the individual overall welfare feeling, the contributions of which can be viewed as different components of the non-economic welfare of electric universal service. In the prospect theory, the calculation of individual utility is based on the probability judgment, and the expected utility of the outcomes to the individual making the decision is composed of the obtained value from the outcome and its probabilities. This theory describes the way people choose between probabilistic alternatives that involve risk, where the probabilities of the outcomes are known, and people evaluate these losses and gains using certain heuristics to make a decision. Inspired by the probability-based expected utility in prospect theory, the calculation method of the non-economic welfare of electric universal service is developed, the concept of which is: if the influencing factors' values of non-economic welfare are supposed to be the different utility levels (corresponding to the obtained value from the outcome in prospect theory), the importance of these factors on non-economic welfare is considered as their probability of occurrence, which can be represented by the indicators' weights (corresponding to the probabilities of outcomes). Therefore, the non-economic welfare of electric universal service can be measured by Equation (3).

$$
S=\Sigma\left(\omega_{i} b_{i}\right)
$$

where $b_{i}$ represents the value of indicator $i$ affecting the non-economic welfare, which can be obtained by individual scoring; $\omega_{i}$ represents the weight of indicator $i$, which can be calculated by a weight determination method, such as analytic hierarchy process (AHP).

The analytic hierarchy process (AHP) method is a multiple criteria decision-making approach created to solve complex multiple criteria problems involving qualitative decisions [23]. The basic principle of using the AHP method to determine the weights of subjective factors are as follows: according to the hierarchical structure based on the interrelationship between indicators, the importance of each indicator within the same layer with regard to the upper layer is compared, and 
then, the importance of each indicator with regard to the final object can be obtained [19,24]. The evaluation index system of the non-economic welfare of electric universal service has a multi-level hierarchical structure, and there is a certain relationship between the subjective indicators. Therefore, the AHP method can be employed to determine the subjective indicator weight in this paper.

\subsection{Social Welfare Evaluation Model of Electric Universal Service}

From the above analysis, the economic welfare of electric universal service can be measured based on the non-dimensional actual economic data, while the non-economic welfare can be measured based on the individual scoring data. According to the meaning of electric universal service, its social welfare can be calculated by Equation (4).

$$
W=\alpha E+\beta S
$$

where $W$ represents the social welfare of electric universal service; $\alpha$ and $\beta$ represent the adjustment coefficient of economic and non-economic welfare, respectively; and $0<\alpha, \beta<1, \alpha+\beta=1$. The function of adjustment coefficient is to adjust the relationship between economic and non-economic welfare of electric universal service in different areas.

Substituting Equations (1)-(3) into Equation (4), the social welfare evaluation model of electric universal service can be obtained, just as shown in Equation (5).

$$
W=\alpha\left(1-\frac{p \times Q}{I \times(1-G) \times N}\right)+\beta \Sigma\left(\omega_{i} b_{i}\right)
$$

In Equation (5), the proportion of electricity consumption expenditure in the national net income can reflect the economic welfare of electric universal service, which takes the unfair income distribution into consideration, combining per capita disposable income and the Gini coefficient, while the non-economic welfare can be reflected by the individual subjective factors values and their corresponding weights.

\section{Empirical Analysis}

This paper takes Yunnan province of China as the example to verify the proposed model and to evaluate the social welfare of electric universal service in China. Yunnan province is an economically less-developed region located in the southwest of China, which is one of the important provinces for implementing electric universal service. As a large agriculture province, Yunnan province has a more than $63.2 \%$ proportion of rural population. Currently, the rural electricity power supply is one of the key issues of electric universal service in Yunnan province. This paper employs the related data of the Yunnan rural area in 2006 and 2011 to evaluate the social welfare of electric universal service.

\subsection{Sample Data}

Through consulting the relevant statistical materials, the indicators' values of economic welfare can be obtained, which are listed in Table 2 . 
Table 2. The indicators' values of economic welfare in 2006 and 2011 (Data source: [25,26]).

\begin{tabular}{lccc}
\hline \multicolumn{1}{c}{ Indicator } & $\mathbf{2 0 0 6}$ & $\mathbf{2 0 1 1}$ & Unit \\
\hline Per capita disposable income & 2041.79 & 4721.99 & Yuan \\
Gini coefficient & 0.512 & 0.372 & - \\
Electricity price level & 0.391 & 0.467 & Yuan $/ \mathrm{kWh}$ \\
Annual electricity consumption & 45.1 & 66.7808 & $10^{8} \mathrm{kWh}$ \\
Population size & 3116 & 2927 & $10^{4}$ \\
\hline
\end{tabular}

Note: the Gini coefficient is no longer being updated since 2007 in China, so the Gini coefficient of Yunnan province in 2011 is calculated by taking "Fujian province statistical yearbook 2012" as the reference.

The indicators of non-economic welfare show a strong subjectivity, and the values can be obtained by questionnaire survey. Through questionnaire investigation and statistics, each indicator's value can be calculated, just as listed in Table 3 .

Table 3. The indicators' values of non-economic welfare in 2006 and 2011.

\begin{tabular}{lccc}
\hline \multicolumn{1}{c}{ Index } & $\mathbf{2 0 0 6}$ & $\mathbf{2 0 1 1}$ & Grading range \\
\hline Income satisfaction degree & 0.67 & 0.79 & $0-1$ \\
Living satisfaction degree & 0.73 & 0.86 & $0-1$ \\
Electric service satisfaction degree & 0.69 & 0.85 & $0-1$ \\
Electric service realization degree & 0.71 & 0.92 & $0-1$ \\
Educational level & 0.61 & 0.66 & $0-1$ \\
Vocational recognition degree & 0.61 & 0.60 & $0-1$ \\
\hline
\end{tabular}

\subsection{Empirical Evaluation}

\subsubsection{Economic Welfare Evaluation}

According to Equation (2) and Table 2, the economic welfare of electric universal service for Yunnan rural areas in 2006 and 2011 can be evaluated, just as follows.

$$
\begin{aligned}
& E_{2006}=1-A_{2006}=1-\frac{p_{2006} \times Q_{2006}}{I_{2006} \times\left(1-G_{2006}\right) \times N_{2006}}=1-0.0568=0.9432 \\
& E_{2011}=1-A_{2011}=1-\frac{p_{2011} \times Q_{2011}}{I_{2011} \times\left(1-G_{2011}\right) \times N_{2011}}=1-0.0359=0.9641
\end{aligned}
$$

From the above calculation results, we can see that the economic welfare level of electric universal service for Yunnan rural areas has increased to 0.9641 in 2011 from 0.9432 in 2006, increasing by $2.21 \%$.

In addition, the single-dimensional sensitivity analysis on the influencing indicators of the economic welfare of electric universal service is performed based on the data in 2006. Set the step size of fluctuation as $5 \%$ and the computation interval as $[-10 \%, 10 \%]$. The sensitivity analysis result is shown in Table 4. 
Table 4. Sensitivity analysis result on the indicators of economic welfare of electric universal service.

\begin{tabular}{ccccc}
\hline \multirow{2}{*}{ Indicator } & $\begin{array}{c}\text { Fluctuation } \\
\text { rate (\%) }\end{array}$ & $\begin{array}{c}\text { Economic } \\
\text { welfare }\end{array}$ & $\begin{array}{c}\text { Change rate of } \\
\text { economic welfare (\%) }\end{array}$ & $\begin{array}{c}\text { Sensitivity } \\
\text { coefficient }\end{array}$ \\
\hline Original data & 0 & 0.9432 & 0 & 0 \\
\hline \multirow{3}{*}{$\begin{array}{c}\text { Per capita disposable } \\
\text { income/population size }\end{array}$} & -10 & 0.9369 & -0.6691 & 0.0669 \\
\cline { 2 - 5 } & -5 & 0.9402 & -0.3169 & 0.0634 \\
\cline { 2 - 5 } & 5 & 0.9459 & 0.2867 & 0.0573 \\
\hline \multirow{3}{*}{ Gini coefficient } & 10 & 0.9484 & 0.5474 & 0.0547 \\
\cline { 2 - 5 } & -10 & 0.9486 & 0.5718 & -0.0572 \\
\cline { 2 - 5 } & -5 & 0.9460 & 0.3001 & -0.0600 \\
\hline \multirow{3}{*}{$\begin{array}{c}n y y y \\
\text { Electricity price level/annual }\end{array}$} & -5 & 0.9401 & -0.3334 & -0.0667 \\
\cline { 2 - 5 } & -10 & 0.9365 & -0.7058 & -0.0706 \\
\cline { 2 - 5 } & -5 & 0.9489 & 0.6022 & -0.0602 \\
\hline
\end{tabular}

According to the sensitivity analysis result, the impact degrees of indicators on economic welfare of electric universal service show the same trend (as shown in Figure 2), which the absolute value of sensitivity coefficient of each indicator maintains at around 0.06 . The economic welfare of electric universal service changes in the same direction with the indicators "per capita disposable income" and "population size", while it becomes the reverse with the indicators "Gini coefficient", "electricity price level" and "annual electricity consumption". This result is consistent with the actual situation, which indicates that the proposed economic welfare evaluation model of electric universal service is reasonable and feasible.

Figure 2. The change of economic welfare with the indicator fluctuation.

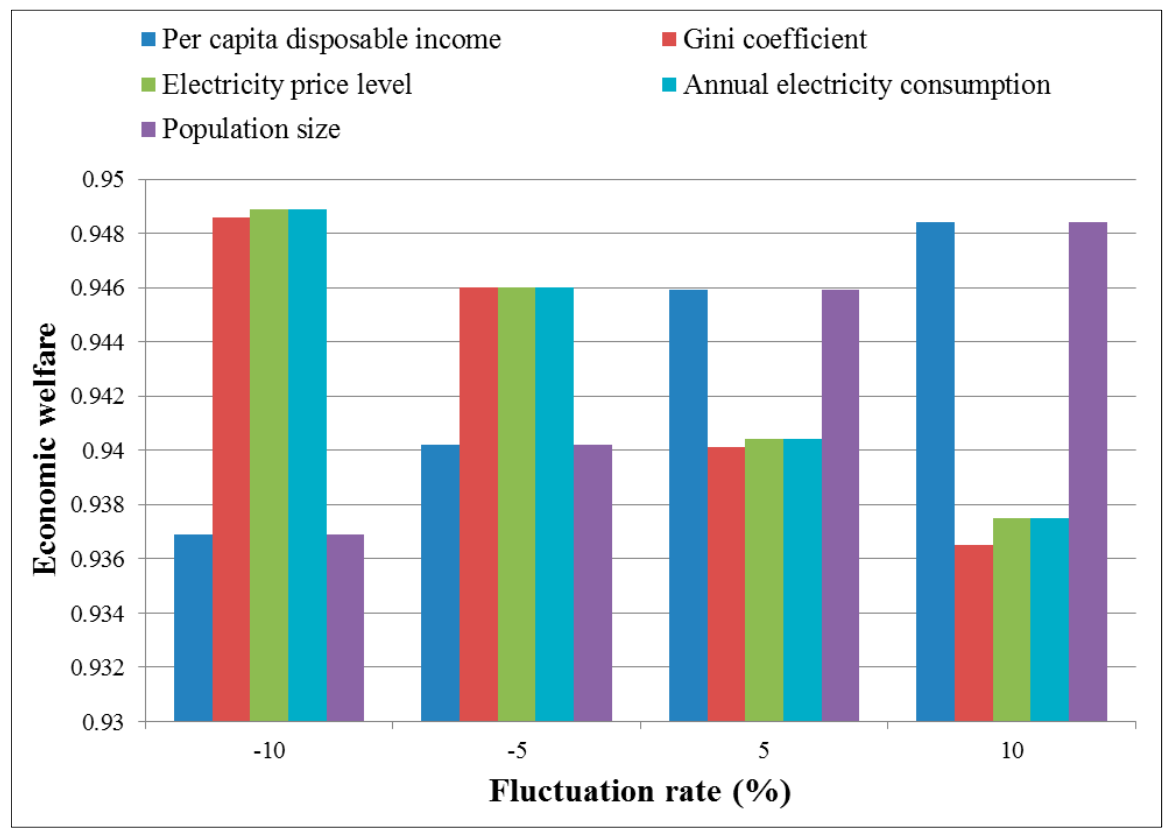




\subsubsection{Non-Economic Welfare Evaluation}

The first step of non-economic welfare calculation is to determine the indicator weight. The AHP method is employed to calculate the indicator weight of non-economic welfare. The judgment matrixes for comparison between every two indicators are listed in Table 5. Then, the eigenvalue $\lambda_{\max }$ equals 6.0138 and the consistency indicator $C R$ equals 0.0022 , which shows that the judgment matrix is consistent. Thus, the indicator weight can be calculated, which is listed in Table 5.

Table 5. Comparison judgment matrix and weight of non-economic welfare indicators.

\begin{tabular}{cccccccc}
\hline Indicator & $\mathbf{B}_{\mathbf{2}}$ & $\mathbf{B}_{\mathbf{4}}$ & $\mathbf{B}_{\mathbf{5}}$ & $\mathbf{B}_{\mathbf{8}}$ & $\mathbf{B}_{\mathbf{9}}$ & $\mathbf{B}_{\mathbf{1 0}}$ & Weight \\
\hline $\mathrm{B}_{2}$ & 1 & 1 & 1 & 0.5 & 2 & 2 & 0.1705 \\
$\mathrm{~B}_{4}$ & 1 & 1 & 1 & 0.5 & 2 & 2 & 0.1705 \\
$\mathrm{~B}_{5}$ & 1 & 1 & 1 & 0.5 & 2 & 2 & 0.1705 \\
$\mathrm{~B}_{8}$ & 2 & 2 & 2 & 1 & 3 & 3 & 0.3098 \\
$\mathrm{~B}_{9}$ & 0.5 & 0.5 & 0.5 & 0.33 & 1 & 1 & 0.0894 \\
$\mathrm{~B}_{10}$ & 0.5 & 0.5 & 0.5 & 0.33 & 1 & 1 & 0.0894 \\
\hline
\end{tabular}

According to Equation (3) and Table 3, the non-economic welfare of electric universal service for Yunnan rural areas in 2006 and 2011 can be evaluated, just as follows.

$$
\begin{aligned}
& S_{2006}=\Sigma\left(\omega_{i} b_{i}\right)=0.6854 \\
& S_{2011}=\Sigma\left(\omega_{i} b_{i}\right)=0.8239
\end{aligned}
$$

From the above calculation results, we can see that the non-economic welfare level of electric universal service for Yunnan rural areas has increased to 0.8239 in 2011 from 0.6854 in 2006, increasing by $20.21 \%$. Therefore, the increase in the non-economic welfare of electric universal service is much larger than that in economic welfare.

In addition, the single-dimensional sensitivity analysis on the indicators of the non-economic welfare of electric universal service is also performed based on the data in 2006. Similarly, set the step size of fluctuation as $5 \%$ and the computation interval as $[-10 \%, 10 \%]$. The sensitivity analysis result is shown in Table 6.

Different from the sensitivity analysis result of economic welfare, the impact degrees of indicators on non-economic welfare of electric universal service are different (as shown in Figure 3), and the sensitivity coefficient value of each factor ranges from 00796 to 0.3209 . The impact degree of the "electric service realization degree" on non-economic welfare is the largest, and its sensitivity coefficient reaches 0.3209 . The following, in order, are those of "living satisfaction degree", "electric service satisfaction degree" and "income satisfaction degree", respectively. While the impact degrees of "educational level" and "vocational recognition degree" on non-economic welfare are relatively low, the result also shows that the sensitivity coefficient values of these six indicators are all positive, which indicates that the non-economic welfare of electric universal service changes in the same direction with indicator fluctuation. This result is consistent with the actual situation, which also indicates that the proposed non-economic welfare evaluation model of electric universal service is reasonable and feasible. 
Table 6. Sensitivity analysis result on the indicators of non-economic welfare of electric universal service.

\begin{tabular}{|c|c|c|c|c|}
\hline Index & $\begin{array}{c}\text { Fluctuation } \\
\text { rate (\%) }\end{array}$ & $\begin{array}{l}\text { Non-economic } \\
\text { welfare }\end{array}$ & $\begin{array}{c}\text { Change rate of } \\
\text { non-economic welfare }(\%)\end{array}$ & $\begin{array}{l}\text { Sensitivity } \\
\text { coefficient }\end{array}$ \\
\hline Original data & 0 & 0.6854 & 0 & 0 \\
\hline \multirow{4}{*}{ Income satisfaction degree } & -10 & 0.6739 & -1.667 & 0.1667 \\
\hline & -5 & 0.6797 & -0.833 & 0.1666 \\
\hline & 5 & 0.6911 & 0.833 & 0.1666 \\
\hline & 10 & 0.6968 & 1.667 & 0.1667 \\
\hline \multirow{4}{*}{ Living satisfaction degree } & -10 & 0.6729 & -1.816 & 0.1816 \\
\hline & -5 & 0.6791 & -0.908 & 0.1816 \\
\hline & 5 & 0.6916 & 0.908 & 0.1816 \\
\hline & 10 & 0.6978 & 1.816 & 0.1816 \\
\hline \multirow{4}{*}{$\begin{array}{c}\text { Electric service satisfaction } \\
\text { degree }\end{array}$} & -10 & 0.6736 & -1.717 & 0.1717 \\
\hline & -5 & 0.6795 & -0.858 & 0.1716 \\
\hline & 5 & 0.6913 & 0.858 & 0.1716 \\
\hline & 10 & 0.6971 & 1.717 & 0.1717 \\
\hline \multirow{4}{*}{$\begin{array}{c}\text { Electric service realization } \\
\text { degree }\end{array}$} & -10 & 0.6634 & -3.209 & 0.3209 \\
\hline & -5 & 0.6744 & -1.605 & 0.3210 \\
\hline & 5 & 0.6964 & 1.605 & 0.3210 \\
\hline & 10 & 0.7074 & 3.209 & 0.3209 \\
\hline \multirow{4}{*}{$\begin{array}{c}\text { Educational } \\
\text { level/vocational } \\
\text { recognition degree }\end{array}$} & -10 & 0.6799 & -0.080 & 0.0080 \\
\hline & -5 & 0.6826 & -0.398 & 0.0796 \\
\hline & 5 & 0.6881 & 0.398 & 0.0796 \\
\hline & 10 & 0.6908 & 0.080 & 0.0080 \\
\hline
\end{tabular}

Figure 3. The change of non-economic welfare with the indicator fluctuation.

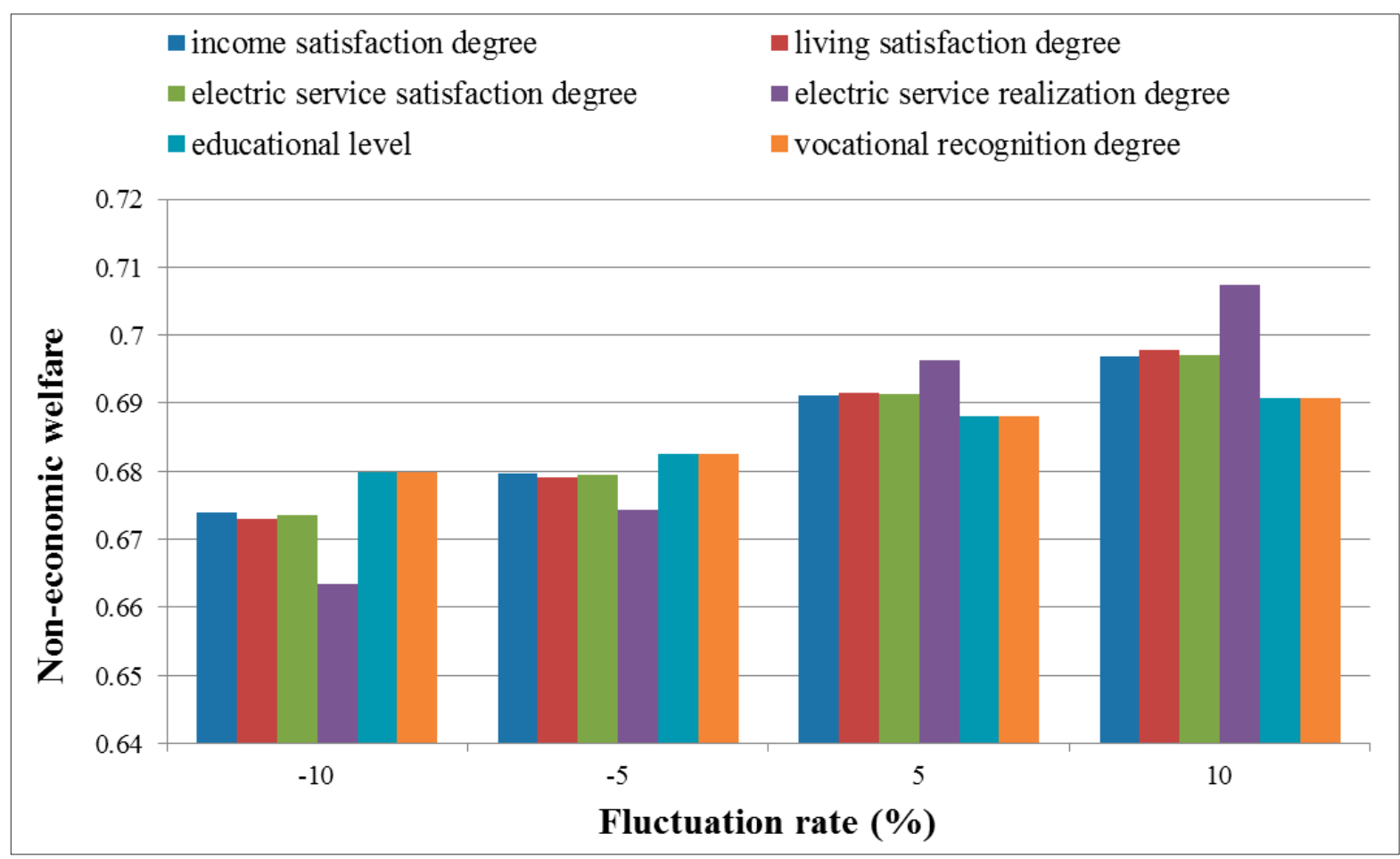




\subsubsection{Social Welfare Evaluation}

When calculating the social welfare, the adjustment coefficients $\alpha$ and $\beta$ need to be determined. In this paper, we suppose $\alpha=\beta=0.5$, which represents that the economic and non-economic welfare of electric universal service are equally important.

Then, the social welfare of electric universal service in Yunnan rural areas in 2006 and 2011 can be calculated, respectively.

$$
\begin{aligned}
& W_{2006}=0.9432 * 0.5+0.6854 * 0.5=0.8143 \\
& W_{2011}=0.9641 * 0.5+0.8239 * 0.5=0.8940
\end{aligned}
$$

From the above calculation results, we can see that the social welfare level of electric universal service for Yunnan rural areas has increased to 0.8940 in 2011 from 0.8143 in 2006, increasing by $9.79 \%$. The implementation effect of electric universal service in Yunnan province is satisfactory.

\section{Conclusions}

Being a public service project, electric universal service has been implemented for several years in China. The effective implementation of electric universal service can improve individual's welfare feeling and promote the sustainable development of people's lives and the local economy to some extent. The research on the social welfare evaluation model of electric universal service can provide a theoretical method for analyzing the welfare effect of electric universal service implementation. Up to now, the studies related to electric universal service are still at the exploratory stage. Therefore, the proposed evaluation model in this paper based on Atkinson's social welfare function and prospect theory from the perspective of sustainability can fill the current research gap related to electric universal service.

According to the proposed evaluation model and empirical analysis, we can safely draw the following conclusions:

(1) The social welfare evaluation model of electric universal service proposed in this paper not only includes the economic welfare, but also considers the non-economic welfare. When evaluating the economic welfare, we pay more attention to the effect of economic benefit to individuals under the consideration of "welfare" concept based on Atkinson's social welfare function. Meanwhile, we employ six subjective indicators to build the non-economic welfare evaluation model of electric universal service by using the ideological connotation of prospect theory.

(2) The empirical analysis results show that the implementation effect of electric universal service in Yunnan province is satisfactory. The social welfare level of electric universal service for Yunnan rural areas has increased to 0.8940 in 2011 from 0.8143 in 2006, increasing by $9.79 \%$. The economic welfare level has increased to 0.9641 in 2011 from 0.9432 in 2006, increasing by $2.21 \%$. The non-economic welfare level has increased to 0.8239 in 2011 from 0.6854 in 2006, increasing by $20.21 \%$. The implementation of electric universal service has significantly improved the welfare level.

(3) The sensitivity analysis results indicate that the impact degrees of indicators on the economic welfare of electric universal service show the same trend, with the absolute value of sensitivity 
coefficient of each indicator remaining at around 0.06; while those on non-economic welfare are different, with the sensitivity coefficient value ranging from 00796 to 0.3209 , and "electric service realization degree" is the most sensitive factor. The policy related to electric universal service improves the individual living quality in remote and underdeveloped areas, which can further promote their sustainable development to some extent.

From the social welfare evaluation result of electric universal service, the Chinese government can identify the implementation effect of electric universal service, which can provide some reference for the relevant policy adjustment. Meanwhile, the proposed social welfare evaluation model of electric universal service has practicability and maneuverability, which can also be applied to other provinces.

\section{Acknowledgments}

This study is supported by the Beijing Sino-foreign Joint Postgraduate Training Co-construction Project, the National Natural Science Foundation of China (Project Number 71373076) and the Humanities and Social Science project of the Ministry of Education of China (Project Number 11YJA790217). The authors would like to thank the editor and anonymous referees.

\section{Author Contributions}

Huiru Zhao initiated the project and conceptualized the paper. Sen Guo analyzed the data and completed the paper in English. Qi Zhang made contributions in data collection and writing material. Chunjie Li gave much good research advice and guided the paper writing.

\section{Conflicts of Interest}

The authors declare no conflict of interest.

\section{References}

1. China's Energy Policy. Available online: http://www.gov.cn/jrzg/2012-10/24/content_2250377.htm (accessed on 6 January 2014).

2. Oğuz, F. Universal service in Turkey: Recent developments and a critical assessment. Telecommun. Policy 2013, 37, 13-23.

3. Hanany, E. The ordinal Nash social welfare function. J. Math. Econ. 2008, 44, 405-422.

4. Sethuraman, J.; Teo, C.P.; Vohra, R.V. Anonymous monotonic social welfare functions. J. Econ. Theor. 2006, 128, 232-254.

5. Trannoy, A. About the right weights of the social welfare function when needs differ. Econ. Lett. 2003, 81, 383-387.

6. Wada, J. A divisor apportionment method based on the Kolm-Atkinson social welfare function and generalized entropy. Math. Soc. Sci. 2012, 63, 243-247.

7. Keller, N. On the probability of a rational outcome for generalized social welfare functions on three alternatives. J. Comb. Theory A 2010, 117, 389-410.

8. Zaharieva, A. Social welfare and wage inequality in search equilibrium with personal contacts. Lab. Econ. 2013, 23, 107-121. 
9. Bruce, N.; Turnovsky, S.J. Social security, growth, and welfare in overlapping generations economies with or without annuities. J. Public Econ. 2013, 101, 12-24.

10. Rousse, O.; Sévi, B. Citizen's participation in permit markets and social welfare under uncertainty. Environ. Sci. Pol. 2013, 27, 215-222.

11. Kim, M.H.; Kim, S.P.; Lee, S. Social-welfare based task allocation for multi-robot systems with resource constraints. Comput. Ind. Eng. 2012, 63, 994-1002.

12. Mæstad, O.; Norheim, O.F. A universal preference for equality in health? Reasons to reconsider properties of applied social welfare functions. Soc. Sci.Med. 2012, 75, 1836-1843.

13. Schlör, H.; Fischer, W.; Hake, J.F. Measuring social welfare, energy and inequality in Germany. Appl. Energ. 2012, 97, 135-142.

14. Nabavi, S.M.H.; Kazemi, A.; Masoum, M.A.S. Social welfare maximization with fuzzy based genetic algorithm by TCSC and SSSC in double-sided auction market. Sci. Iran. 2012, 19, 745-758.

15. Lipow, J.; Simon, J. Military reserves and social welfare. Econ. Lett. 2011, 113, 208-210.

16. Murakami, H. Time effect of low-cost carrier entry and social welfare in US large air markets. Transport. Res. E-Log. 2011, 47, 306-314.

17. Pirnia, M.; Nathwani, J.; Fuller, D. Ontario feed-in-tariffs: System planning implications and impacts on social welfare. Elec. J. 2011, 24, 18-28.

18. Kanakasabapathy, P. Economic impact of pumped storage power plant on social welfare of electricity market. Int. J. Elec. Power Energ. Syst. 2013, 45, 187-193.

19. Zhao, H.; Guo, S. Risk Evaluation on UHV Power Transmission Construction Project Based on AHP and FCE Method. Math. Probl. Eng. 2014, 2014, 1-14.

20. Atkinson, A.B. On the measurement of inequality. J. Econ. Theor. 1970, 2, 244-263.

21. Kahneman, D.; Tversky, A. Prospect theory: An analysis of decision under risk. Econ. J. Econ. Soc. 1979, 47, 263-291.

22. Tversky, A.; Kahneman, D. Advances in prospect theory: Cumulative representation of uncertainty. J. Risk Uncertain. 1992, 5, 297-323.

23. Saaty, T.L. The Analytic Hierarchy Process; Mac Gray-Hill: New York, NY, USA, 1980.

24. Li, H.Z.; Guo, S. External economies evaluation of wind power engineering project based on analytic hierarchy process and matter-element extension model. Math. Probl. Eng. 2013, 2013, 1-11.

25. China National Bureau of Statistics. China Statistical Yearbook 2007; China Statistics Press: Beijing, China, 2007.

26. China National Bureau of Statistics. China Statistical Yearbook 2012; China Statistics Press: Beijing, China, 2012.

(C) 2014 by the authors; licensee MDPI, Basel, Switzerland. This article is an open access article distributed under the terms and conditions of the Creative Commons Attribution license (http://creativecommons.org/licenses/by/3.0/). 